OPEN ACCESS

Edited by: Xiangzhong $\mathrm{Li}$,

Yunnan University, China

Reviewed by: Yangtong Cao,

Chinese Academy of Geological

Sciences, China

Yuan-Yuan Lü,

Chinese Academy of Geological

Sciences, China

*Correspondence:

Xiying Zhang

xyzhchina@isl.ac.cn

Mingyue $\mathrm{Hu}$

luna010_w@163.com

Specialty section:

This article was submitted to

Quaternary Science, Geomorphology

and Paleoenvironment,

a section of the journal

Frontiers in Earth Science

Received: 21 April 2021

Accepted: 25 May 2021

Published: 15 June 2021

Citation:

Li J, Zhang X, Hu M, Li W, Miao W,

Yuan X, Li Y, Tang $Q$, Han W and Ma H

(2021) Halogenases of Qarhan Salt

Lake in the Qaidam Basin: Evidence

From Halite Fluid Inclusions.

Front. Earth Sci. 9:698229.

doi: 10.3389/feart.2021.698229

\section{Halogenases of Qarhan Salt Lake in the Qaidam Basin: Evidence From Halite Fluid Inclusions}

\author{
Jun $\mathrm{Li}^{1,2,3}$, Xiying Zhang ${ }^{1,2 *}$, Mingyue $\mathrm{Hu}^{4 *}$, Wenxia $\mathrm{Li}^{1,2,3}$, Weiliang Miao ${ }^{1,2}$, Xiaolong Yuan ${ }^{1,2}$, \\ Yongshou $\mathrm{Li}^{1,2}$, Qiliang Tang ${ }^{1,2}$, Wenxia $\mathrm{Han}^{5}$ and Haizhou Ma ${ }^{1,2}$ \\ ${ }^{1}$ Key Laboratory of Comprehensive and Highly Efficient Utilization of Salt Lake Resources, Qinghai Institute of Salt Lakes, Chinese \\ Academy of Sciences, Xining, China, ${ }^{2}$ Qinghai Provincial Key Laboratory of Geology and Environment of Salt Lakes, Qinghai \\ Institute of Salt Lakes, Chinese Academy of Sciences, Xining, China, ${ }^{3}$ University of Chinese Academy of Sciences, Beijing, China, \\ ${ }^{4}$ National Research Center for Geoanalysis, Beijing, China, ${ }^{5}$ College of Resources and Environment, Linyi University, Linyi, China
}

The fluid inclusion composition of halite can help track chemical composition of ancient fluids and, thus, serves as a reliable index to analyze ancient brine in salt lakes. Qarhan Salt Lake (QSL) is the largest potash brine deposit in China. Although the mixing of modern river water and $\mathrm{Ca}-\mathrm{Cl}$ deep water is widely accepted as potassium formation, the mixing characteristics in the time domain and driving factors of deep water are still unclear. Here, the chemical composition of fluid inclusions in primary halite samples collected from the ISL1A borehole in QSL was measured by LA-ICP-MS technology. The analysis results show that, during the formation stage of the $S_{4}$ salt layer in QSL, the main potassium salt layer, the contents of $\mathrm{Ca}^{2+}$ and $\mathrm{Sr}^{2+}$ in brine increased significantly. There is evidence confirming that $\mathrm{Ca}-\mathrm{Cl}$ deep water is beneficial to the enrichment of potassium and the surrounding rivers generally develop terraces. It suggests that, during the formation stage of the QSL potassium salt layer, more $\mathrm{Ca}-\mathrm{Cl}$ inflow water of the northern margin supplies the salt lake, inferring that it was driven by tectonic activities. In addition, the chemical composition of halite fluid inclusions shows that there is an anomaly in geochemistry at the early stage of salt formation in QSL. By combining the time of tectonic activities, it is inferred that the anomaly is not caused by tectonic activities but maybe caused by a salt-forming event. This work indicates that deep water and tectonic movement have a huge impact on the evolution of salt lakes. Therefore, it is necessary to consider the influence of deep water and tectonic activities on the salt-forming evolution stage of salt lakes when studying the salt-forming evolution stage of salt lakes and paleoclimate by using salt lake deposition.

Keywords: Qaidam Basin, Qarhan Salt Lake, Ca-Cl brines, halogenases, halite fluid inclusions, tectonic activities

\section{INTRODUCTION}

As an important part of the Tibetan Plateau (TP), the Qaidam Basin (QB) is located in the north of the TP and occupied by a large number of salt lakes having potassium, lithium, and boron salt resources. Qarhan Salt Lake (QSL) is the largest salt lake in the QB and has always been the hot and typical spot for studying the evolution and environmental changes of modern salt lakes (Yang et al., 1995; Yu, 2000; Fan et al., 2018; Li et al., 2020; He et al., 2020).

The beginning of salt formation in QSL was about $50 \mathrm{ka}$ ago, and the whole process is divided into three stages during which the main salts were deposited (Zhang et al., 1990; Zhang et al., 1993; Fan 
et al., 2015). Except for the impact of the climate changes on the evolution of QSL, the mixing of different brines also played an important role during the evolution of the salt lake (Yuan and Duan, 1989). It is found that the formation of potassium-bearing brine in QSL is the result of the mixing of river water and $\mathrm{Ca}-\mathrm{Cl}$ deep water (Lowenstein et al., 1989; Zhang et al., 1993), which is confirmed by Pitzer model simulation (Liu et al., 2002). The study of mineral assemblage in different sections of the QSL surface also indicated the existence of the mixing phenomenon in different water bodies (Yi et al., 2017). A recent study argues that mixing probably continued the whole process of salt formation (Fan et al., 2018) and exerted important influence on the formation of salts (Li et al., 2020). In a word, the mixing process of magnesium sulfate subtype water and calcium chloride-type water controls the enrichment of QSL. However, although many studies on mixing existing in the modern QSL have been carried out, only few studies focus on ancient salts. Therefore, it is not so clear whether mixing happened in the evolution history of QSL. Determining the driving mechanism of mixing is even more interesting.

The analysis of fluid inclusion in halite is a direct and effective method to indicate the evolution of saline fluid/paleo-brine in ancient and modern evaporite basins (Goldstein and Reynolds, 1994; Meng et al., 2011, 2012; Weldgehebriel et al., 2020). In this paper, the chemical composition of primary fluid inclusion in halite from the ISL1A borehole drilled in the north QSL is studied. Based on the information from fluid inclusion in halite, we will make an attempt to identify the mixing of brines and discuss its influence on halogenases of QSL.

\section{Geological Setting}

The QB is a large intermontane basin on the northeastern Tibetan Plateau. The formation and evolution of the QB are influenced by the Altyn Tagh left strike-slip fault system, Kunlun thrust fault system, and Qilian Mountain south thrust system. Its active tectonic activity and developed faults provide a channel and power for a Ca-Cl-type deep hydrothermal brine to deposit in lakes (Zhang, 1987; Ren et al., 2006; Lowenstein and Risacher, 2009). There is a thrust fault extending for hundreds of kilometers from northwest to southeast in the basin, and the $\mathrm{Ca}-\mathrm{Cl}$ deep hydrothermal brine in the Huobuxun section of QSL is upwelling along this fault (Zhang, 1987; Lowenstein et al., 1989). The distribution of salt lakes in the QB is mainly controlled by geological structural factors. According to its relationship with structural units, it can be divided into three salt lake areas: Mangya fault depression, central strong depression, and Qilian Mountain front block fault zone (Yuan, 1959; Zhang, 1987) (Figure 1A). The combined presence of ambient high mountains with altitudes $>4000 \mathrm{~m}$ and a low basin with altitudes ranging from 2600 to $3200 \mathrm{~m}$ in the QB, as well as the secular drying of the climate and environment within the basin during the Cenozoic, favors the formation of salt deposits (Yuan et al., 1983; Zhang, 1987). Thus, more than 30 salt lakes with rich thick salt beds and brines are distributed in the basin (Zhang, 1987). QSL lies in the eastern part of the QB and covers an area of $5856 \mathrm{~km}^{2}$. Nowadays, QSL is almost a "dry lake," with only some brine lakes remaining in the eastern, western, and southern margins (Zhang, 1987; Zheng et al., 2002; Huang and Han, 2007) (Figure 1B).

The Sanhu depression, the eastern depression of the $\mathrm{QB}$, is abundant in biogenic gas and brine-salt resources (Li et al., 2020). QSL is located in the Sanhu depression and southeast of the QB. Both the north and south sides of the lake are compressional and torsional deep faults, and the salt accumulation area is located in this graben depression. Geological development is dominated by subsidence, and thousands of meters of sediments have accumulated in the lake area. There are nine surface brine lakes distributed within the margin of the playa, including North Huobuxun Lake, South Huobuxun Lake, Xiezuo Lake, Senie Lake, Tuanjie Lake, Dabuxun Lake, Dongling Lake, Dabiele Lake, and Xiaobiele Lake (Figure 1B). These marginal brine lakes are not residual lakes but formed through river and spring water inflows following the formation of the salt playa (Chen et al., 1981). Accompanied by the change in climate, the sediments also appeared alternately as salt layers and clastic layers (Zhang et al., 2003) and ultimately formed a super-large salt deposit mainly composed of salt intercrystalline brine.

Salt-bearing strata in the mining area are mainly lacustrine fine clastic and chemical sedimentary formations since Quaternary. Fine clastic formations are mainly silt and clay, while chemical sedimentary formations are mainly halite formations ( $\mathrm{Hu}, 1990)$. The salt deposits in QSL can be divided into four layers from bottom to top (Figure 2), namely, $S_{1}, S_{2}, S_{3}$, and $S_{4}$. The potassium deposit mainly exists in the upper $S_{4}$ layer (Yang, 1982; Huang and Cai, 1987).

\section{MATERIALS AND METHODS}

The borehole ISL1A $\left(37^{\circ} 3^{\prime} 50^{\prime \prime} \mathrm{N}, 94^{\circ} 43^{\prime} 41^{\prime \prime} \mathrm{E}\right)$ is located in the Bieletan section of QSL (Figure 1B), and the lithology and sedimentary characteristics of the borehole have been described in previous studies (An et al., 2013; Fan et al., 2014; Wei et al., 2015; Miao et al., 2016). Totally, the upper part of ISL1A (0-51.0 m) consists of halite, silty sand, and clay. The lower part of ISL1A (51.0-102.0 m) consists of silty sand and clay with organic matter and no evaporites. Here, the halite from the upper evaporite section was sampled for further study. The ISL1A borehole core profile shows that salt suddenly begins to form at $51 \mathrm{~m}$ (An, 2012; Zhang, 2020), but there is no formed halite crystal until about $45 \mathrm{~m}$, so the sample is selected from $43.46 \mathrm{~m}$.

\section{Samples and Observation}

According to the sedimentary characteristics, 12 halite samples were selected for petrographic observation to test composition. The processing method refers to the method of Benison and Goldstein, 1999. In order to avoid damaging the fluid inclusions of halite, firstly, the halites selected with better crystal form are peeled off along the cleavage plane with a knife and made into $0.5-1 \mathrm{~mm}$ slices (Figure 3). After that, they are observed under a microscope with single polarized light. The identification of primary halite, which has the characteristics of the chevron and cumulate inclusion zone, refers to previous works (Haride et al., 1983; Lowenstein and Haride, 1985; Zhang et al., 1990). The 


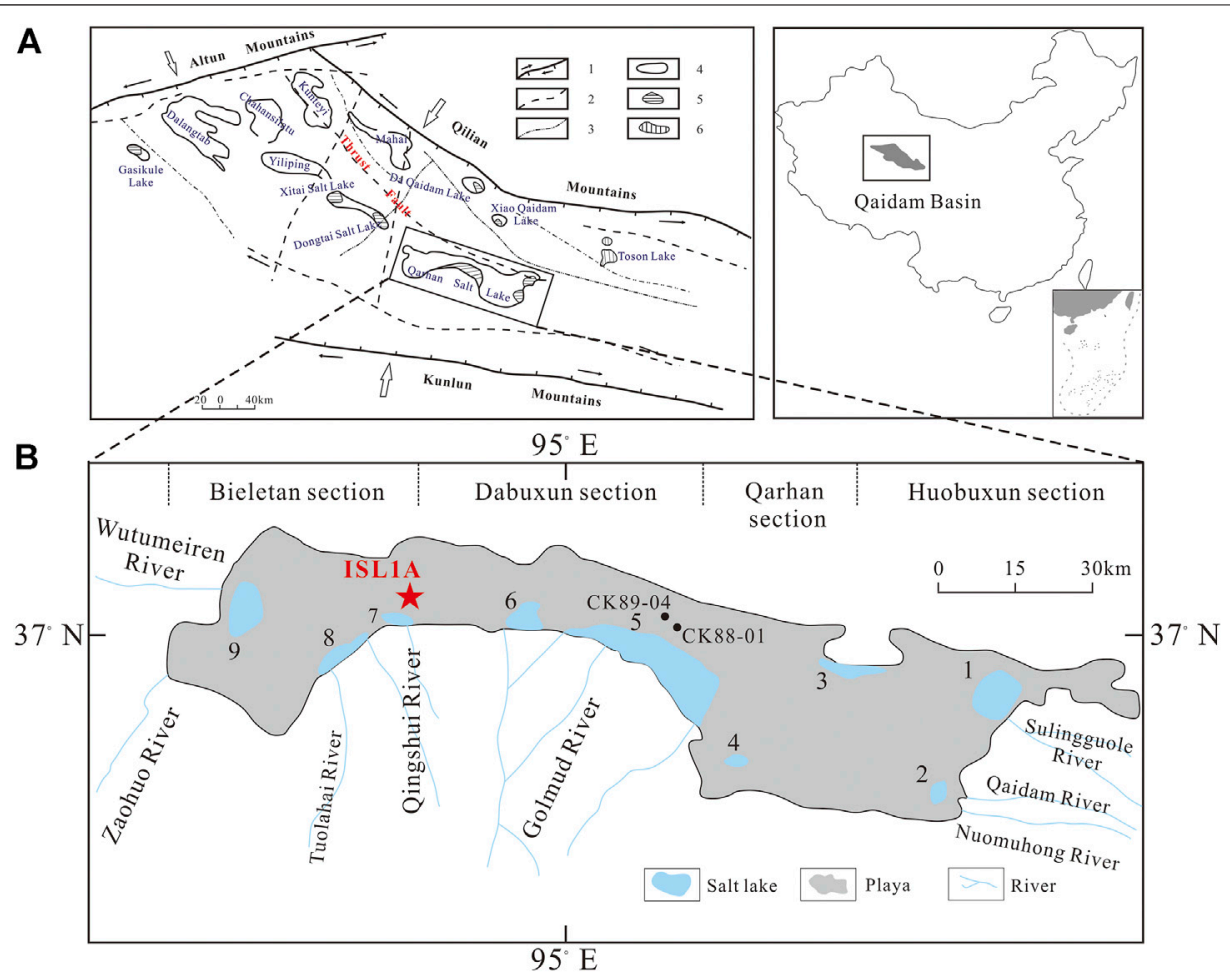

FIGURE 1 | Tectonic outline and salt lakes in the QB (Li et al., 2020). (A) Map showing the tectonic divisions of the QB and the location of Qarhan Salt Lake (QSL). 1: grade I structural line controlling the boundary of the Qaidam ancient block; 2: grade II structural line controlling the Qaidam Basin; 3: grade III structural line controlling the salt lake belt; 4: salt playa; 5: brine lake; 6: brackish water lake. (B) Location of drillholes ISL1A, CK89-04, and CK88-01 in QSL.

samples were observed and screened with reference to the standards above. The result of observation shows that the inclusions are mainly single liquid phase, more than $90 \%$ of which are regular cubes. The size is within $10-30 \mu \mathrm{m}$ and occasionally larger more than $100 \mu \mathrm{m}$ (Figure 4).

\section{Analytical Methods}

The chemical composition of halite fluid inclusions was measured at the National Research Center for Geoanalysis of the Chinese Academy of Geological Sciences, by the LA-ICP-MS method, using an Element 2 plasma mass spectrometer (Finnigan Company, Germany) and UP 213 laser (New Wave Company). The halite slice was fixed on the glass slide, and the glass slide was placed in the laser ablation chamber. The laser beam with a wavelength of $193 \mathrm{~nm}$ and beam spot of $50 \mu \mathrm{m}$ was focused on the surface of the sample for single-point ablation, with a pulse frequency of $8 \mathrm{~Hz}$, pulse energy of $0.26 \mathrm{~mJ}$, output energy of $80 \%$, and energy density of about $16 \mathrm{~J} / \mathrm{cm}^{2}$. The background collection time of ICP-MS is $20 \mathrm{~s}$, and the denudation time is $160 \mathrm{~s}$. Because this method cannot know the volume of inclusions and needs the comparison of elements with known concentrations, the calibration method adopts the combination of internal and external standards ( $\mathrm{Hu}$ et al., 2008; Sun et al., 2013). In the external standard method, the prepared standard solution was drawn into a pure quartz capillary tube and quickly sealed with epoxy resin. During the test and analysis, manufactured artificial fluid inclusions were attached to a glass sheet with double-sided adhesive and put into a laser ablation sample chamber together with test samples. In the internal standard method, $\mathrm{Na}$ was selected as the internal standard element for halite fluid inclusion samples, and the $\mathrm{Na}$ content was calculated to be $141.62 \mathrm{~g} / \mathrm{L}$ based on the theoretical value. It is assumed that the relative sensitivity between the standard calibration instrument and elements in the unknown sample remained unchanged; that is, calibration was carried out according to the consistency of changes in the internal standard element and elements to be measured (Longerich et al., 1996; Hu et al., 2008).

\section{RESULTS}

\section{Age of Samples}

Fan et al. (2014) established the chronological linear regression equation of the ISL1A borehole, which is $\mathrm{y}=1.2091 \mathrm{x}-10.266$; here, the ordinate is the sampling depth, and the horizontal ordinate represents age. By the interpolation method, the age of the samples in this study is obtained (Figure $\mathbf{5}$ and Table $\mathbf{1}$ ).

\section{Chemical Composition of Fluid Inclusion in Halite}

In this study, the chemical composition of 171 halite fluid inclusions in 12 halite samples was determined by LA-ICP-MS 


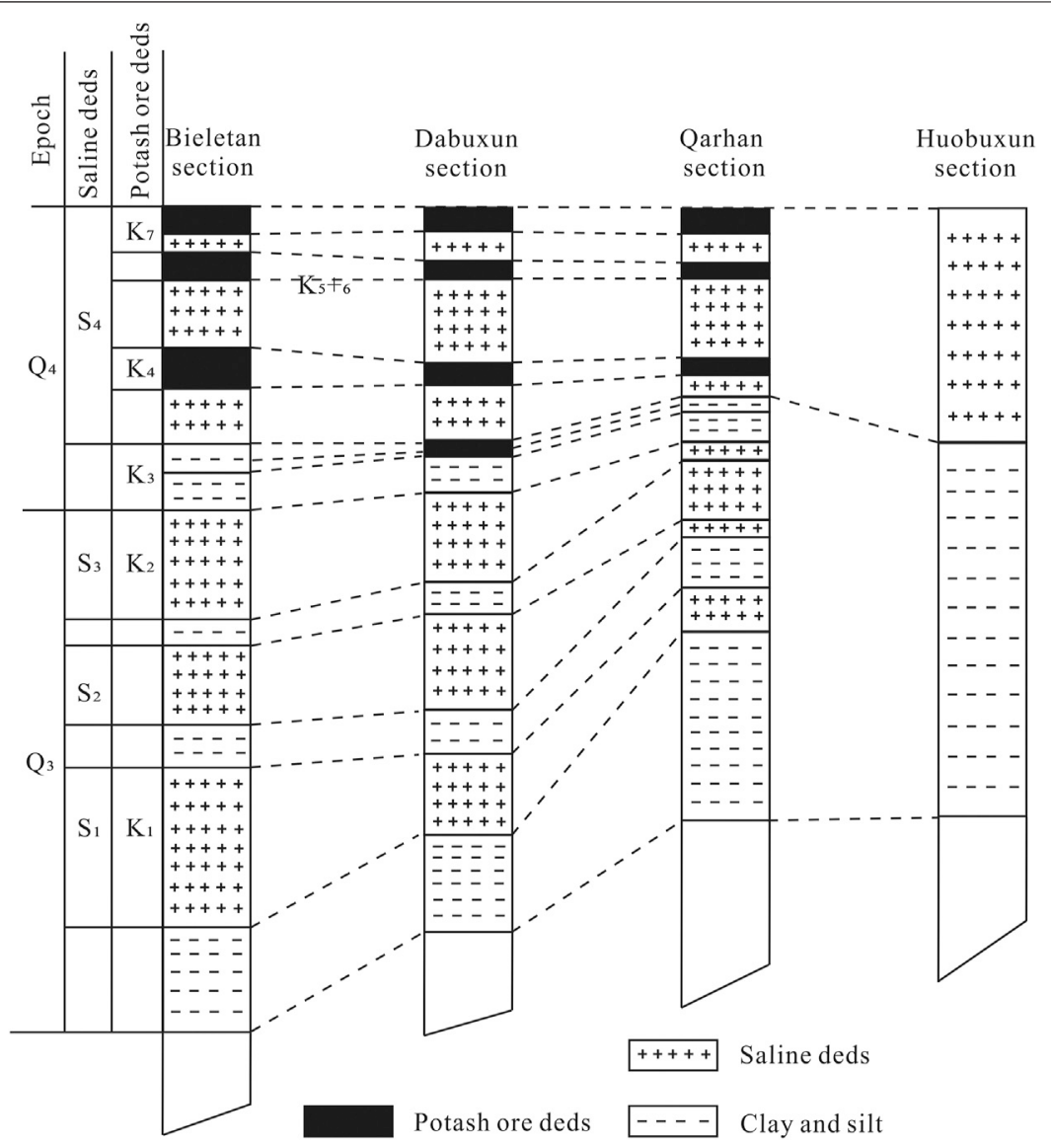

FIGURE 2 | Comparison sketch of the potash ore beds with saline beds in different sectors in Qarhan saline lake from Yang (1982).

technology. Due to the large number of halite fluid inclusions we measured, here we only list the average concentration of ions in each halite sample after data processing (Table 1). There are two significant inflection points in the longitudinal variation tendency of $\mathrm{Mg}^{2+}, \mathrm{K}^{+}, \mathrm{Ca}^{2+}, \mathrm{Br}^{-}, \mathrm{Sr}^{2+}, \mathrm{Li}^{+}, \mathrm{B}^{3+}$, and $\mathrm{Rb}^{+}$contents in the evaporation salt layer in the upper part of the ISL1A borehole. From the beginning of salt formation to $25.32 \mathrm{~m}$, the ion content decreased at the same time and then increased significantly at $11.10 \mathrm{~m}$, which divided the variation tendency of data into three parts (Table 1 and Figure 6). The study of $\delta \mathrm{D}$ and $\delta^{18} \mathrm{O}$ shows that the evolution of QSL can be divided into three stages (Lowenstein et al., 1994; Yang et al., 1995; Zhang et al., 1995). Meanwhile according to the sedimentary characteristics of the evaporation salt layer in the upper part of ISL1A, we share its three salt-bearing layers (Fan et al., 2015; Du et al., 2019). In this study, the variation tendency of the ion content can also be divided into three stages (Figure 6), which is confirmed by the three stages of salt formation in QSL. It reflects the evolution process of QSL from concentration to desalination and concentration again. But there are two anomalies that deserve attention. The one is that $\mathrm{Mg}^{2+}, \mathrm{Br}^{-}, \mathrm{K}^{+}$, and $\mathrm{B}^{3+}$ contents, which reflect the concentration degree of the salt lake, are higher at an early stage of salt formation, especially $\mathrm{Mg}^{2+}$ and $\mathrm{Br}^{-}$reaching $64.62 \mathrm{~g} / \mathrm{L}$ and $19.58 \mathrm{mg} / \mathrm{L}$, respectively. Another abnormal phenomenon is that, during the middle and late evolution of QSL, the enrichment stage of potassium and magnesium, the contents of $\mathrm{Ca}^{2+}$ and $\mathrm{Sr}^{2+}$ increased suddenly at the same time, and the peak values reached $11.22 \mathrm{~g} / \mathrm{L}$ and $244.25 \mathrm{mg} / \mathrm{L}$, respectively.

\section{DISCUSSION}

\section{Ca-Cl Deep Water During Halogenases in QSL}

A previous study argues that the $\mathrm{Ca}-\mathrm{Cl}$ deep water supply and mixing probably continued the whole process of salt formation in QSL (Fan et al., 2018), but the specific change in supply quantity is not clear. According to the $\delta \mathrm{D}$ and $\delta^{18} \mathrm{O}$ characteristics of the fluid inclusions in the primary halite of ZK88-01 and ZK89-04 in QSL, we share the salt-forming environment of the salt lake's three stages: I, II, and III partitions represent three ranges of variation from bottom to top (Zhang et al., 1990; Zhang et al., 1995) (Figure 6). In the first stage (depth $>23 \mathrm{~m}$ ), $\delta \mathrm{D}$ and $\delta^{18} \mathrm{O}$ values are large and very close (Figure $6 \mathrm{I}$ ), indicating that the salt lake is in a stable drying stage. In addition, because $\delta \mathrm{D}$ vs. $\delta^{18} \mathrm{O}$ is located in the upper right of the evaporation line in the study area, it does not completely fall on the evaporation line (Figure 6 I), 


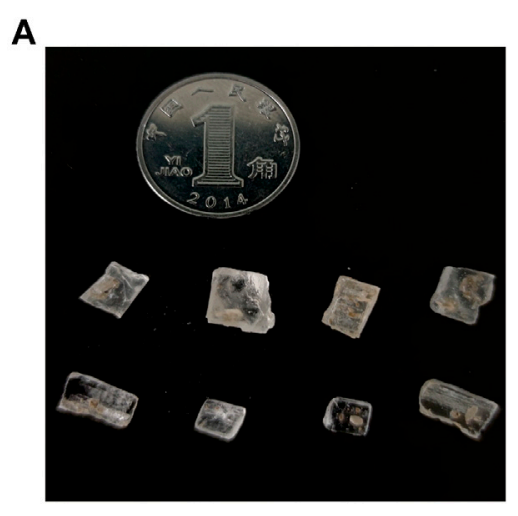

c

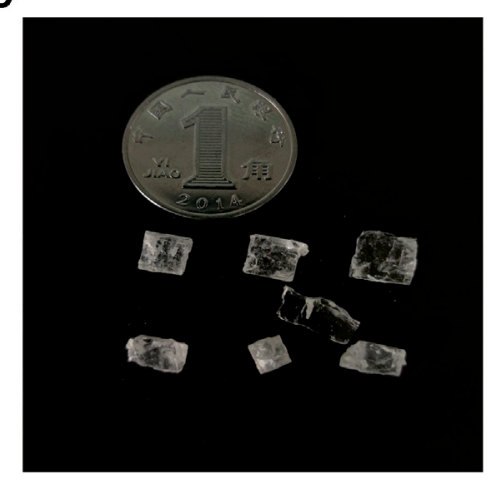

B

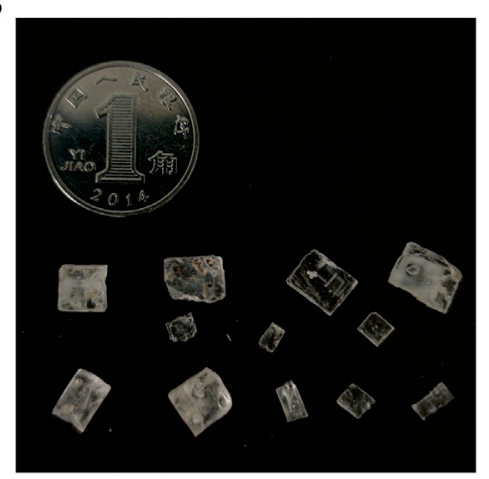

D

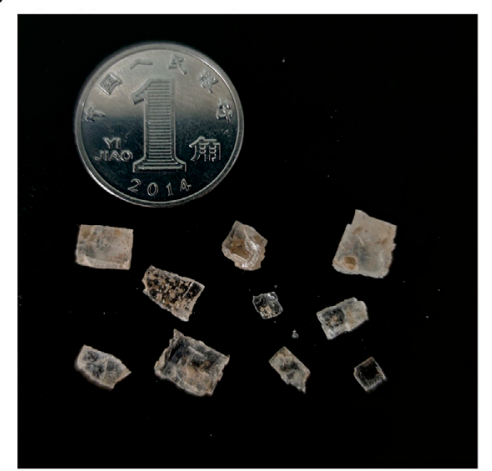

FIGURE 3 | Halite debris particles from the ISL1A drillhole. (A,D) Halite crystals and chips mixed with clay and silt that were prepared by cleaving 0.5-1 mm thickness with a razor blade. $(\mathbf{B}, \mathbf{C})$ Typical halite idiomorphic crystals and chips without clay and silt.

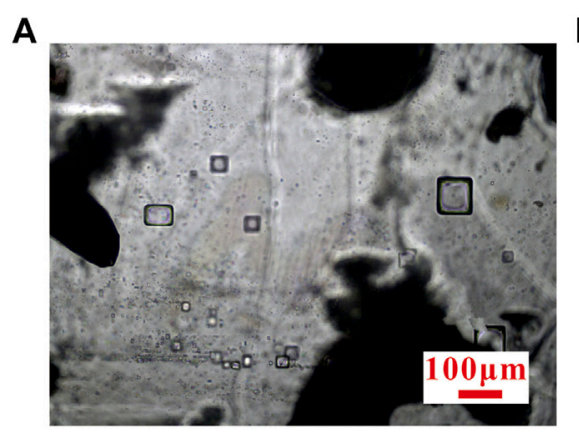

B

C

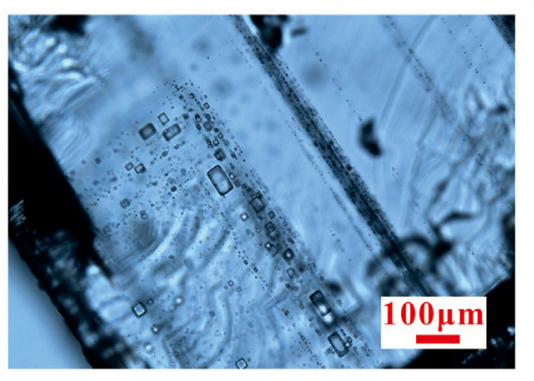

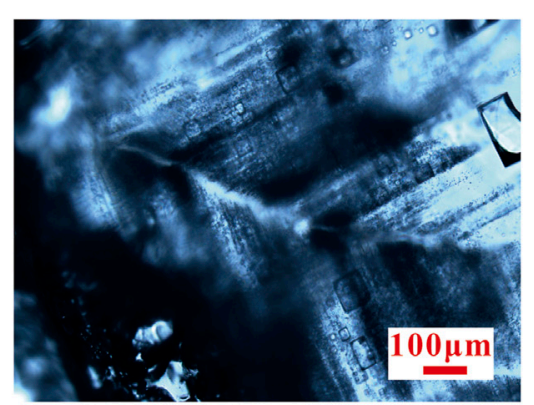

D

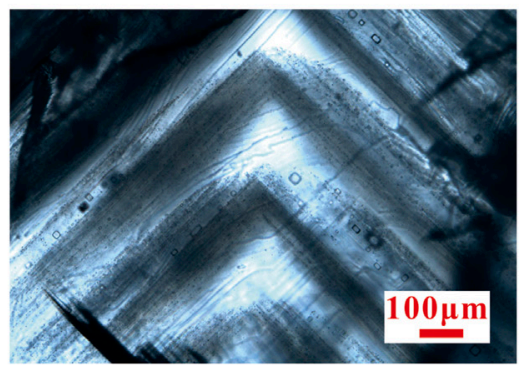

FIGURE 4 | Petrologic characteristics of halite fluid inclusions. (A) Irregular dispersion of primary halite fluid inclusions. (B,D) Parallel fluid inclusion bands in hopper primary crystals that form bright and dark bands with host minerals, with dark ones being fluid inclusion groups. (C) Primary halite fluid inclusions regularly distributed along the crystal growth. 


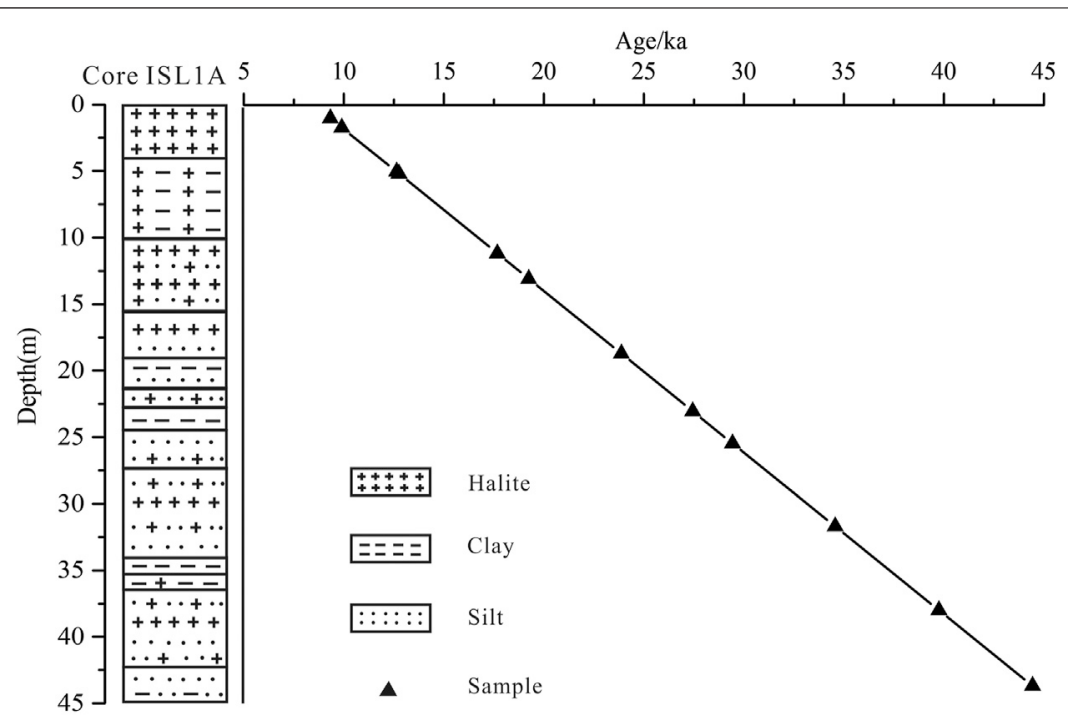

FIGURE $\mathbf{5}$ | Age and depth of halite samples in this study.

TABLE 1 | Chemical components of fluid inclusions in halites from the ISL1A drillhole.

\begin{tabular}{|c|c|c|c|c|c|c|c|c|c|c|c|}
\hline \multirow[t]{2}{*}{ Content } & \multirow[t]{2}{*}{ Depth (m) } & \multirow[t]{2}{*}{ Age (ka) } & \multirow[t]{2}{*}{$\mathbf{n}$} & \multicolumn{3}{|c|}{ Avg. $\rho(B)(g / L)$} & \multicolumn{5}{|c|}{ Avg. $\rho(B)(m g / L)$} \\
\hline & & & & $\mathbf{M g}$ & $K$ & $\mathrm{Ca}$ & $\mathrm{Br}$ & $\mathrm{Sr}$ & Li & B & $\mathbf{R b}$ \\
\hline Q-1 & 1.00 & 9.32 & 59 & 101.71 & 46.36 & 1.92 & 0.00 & 33.21 & 118.47 & 107.70 & 3.91 \\
\hline Q-2 & 1.70 & 9.89 & 9 & 49.37 & 10.52 & 0.19 & 19.62 & 7.26 & 60.07 & 134.19 & 2.61 \\
\hline Q-3 & 5.00 & 12.64 & 9 & 214.73 & 43.33 & 4.58 & 0.00 & 54.68 & 94.57 & 44.13 & 19.93 \\
\hline Q-4 & 5.15 & 12.75 & 17 & 194.89 & 25.14 & 0.98 & 16.58 & 14.81 & 196.28 & 197.11 & 7.35 \\
\hline Q-5 & 11.10 & 17.67 & 4 & 137.23 & 46.89 & 11.22 & 18.93 & 244.25 & 183.38 & 62.47 & 11.77 \\
\hline Q-6 & 13.00 & 19.24 & 11 & 190.38 & 41.57 & 9.02 & 0.00 & 180.45 & 119.83 & 53.76 & 11.49 \\
\hline Q-7 & 18.60 & 23.87 & 10 & 16.91 & 5.28 & 0.62 & 3.80 & 11.51 & 8.89 & 8.94 & 0.89 \\
\hline Q-8 & 22.91 & 27.44 & 13 & 19.38 & 5.64 & 1.31 & 5.46 & 28.98 & 15.50 & 21.49 & 1.75 \\
\hline Q-9 & 25.32 & 29.43 & 8 & 5.07 & 1.62 & 0.33 & 3.90 & 7.31 & 8.69 & 7.47 & 0.68 \\
\hline$Q-10$ & 31.52 & 34.56 & 13 & 9.45 & 2.25 & 0.22 & 4.86 & 4.22 & 25.21 & 22.70 & 0.68 \\
\hline Q-11 & 37.79 & 39.75 & 13 & 27.72 & 5.91 & 0.66 & 8.88 & 33.40 & 60.90 & 50.40 & 2.44 \\
\hline Q-12 & 43.46 & 44.43 & 5 & 64.62 & 13.04 & 0.43 & 19.58 & 10.33 & 68.01 & 140.17 & 1.80 \\
\hline
\end{tabular}

which proves that the hydrological characteristics of the ancient lake at this time are not controlled by evaporation factors alone, and there may be a situation of high salt brine replenishment. In the second stage $(8-23 \mathrm{~m}), \delta \mathrm{D}$ vs. $\delta^{18} \mathrm{O}$ deviates significantly from the evaporation line in the study area (Figure 6 II), which indicates that there should be a large amount of $\delta \mathrm{D}$ - and $\delta^{18} \mathrm{O}$-poor water supply in the lake area at this time. In the third stage (depth $<8 \mathrm{~m}$ ), $\delta \mathrm{D}$ vs. $\delta^{18} \mathrm{O}$ is all distributed on the evaporation line in the study area (Figure 6 III), indicating that the hydrological characteristics of the lake at this time are mainly controlled by temperature rise and evaporation (Zhang et al., 1990).

In view of the characteristics of rich $\mathrm{Sr}^{2+}$ and $\mathrm{Ca}^{2+}$ in deep water, $\rho\left(\mathrm{Ca}^{2+}\right)$ and $\rho\left(\mathrm{Sr}^{2+}\right)$ of halite fluid inclusions in the ISL1A borehole are compared with the $\delta \mathrm{D}$ contents of CK89-04 and CK88-01, and there is an obvious negative correlation near $10 \mathrm{~m}$ (Figure 9). The normal salt precipitation sequence shows that the deposition of potassium and magnesium salts, expressed by enrichment of potassium and magnesium ions, will not be accompanied by the abnormal enrichment of $\mathrm{Ca}^{2+}$ ions $(\mathrm{Hu}$, 1991). However, the deposition of potassium and magnesium salts in QSL was accompanied by abnormally enriched $\mathrm{Ca}^{2+}$ in the ISL1A borehole (Figure 7). Meanwhile, unpublished data show that polyhalite $\left(\mathrm{K}_{2} \mathrm{Ca}_{2} \mathrm{Mg}\left[\mathrm{SO}_{4}\right]_{4} \cdot 2 \mathrm{H}_{2} \mathrm{O}\right)$ appears in the stage of abnormal $\mathrm{Ca}^{2+}$ enrichment. The polyhalite found in the saltbearing strata of QSL is considered to be a primary mineral formed by fluid mixing (Sun and Lock, 1988). Not only $\mathrm{Ca}^{2+}$ but also $\mathrm{Sr}^{2+}$ is abnormally enriched (Figure 7), and Ca-Cl deep waters and brines are enriched with $\mathrm{Sr}^{2+}$ and $\mathrm{Ca}^{2+}$ in QSL (Fan et al., 2018). However, the $\mathrm{Br}^{-}$content, which reflects the salt lake concentration, did not increase abnormally but increased gradually (Figure 9). The formation of $\mathrm{MgSO}_{4}$-deficient evaporites in QSL (Zhang et al., 1991; Li et al., 2020) also indicates that the lake has been replenished by $\mathrm{Ca}-\mathrm{Cl}$ deep 


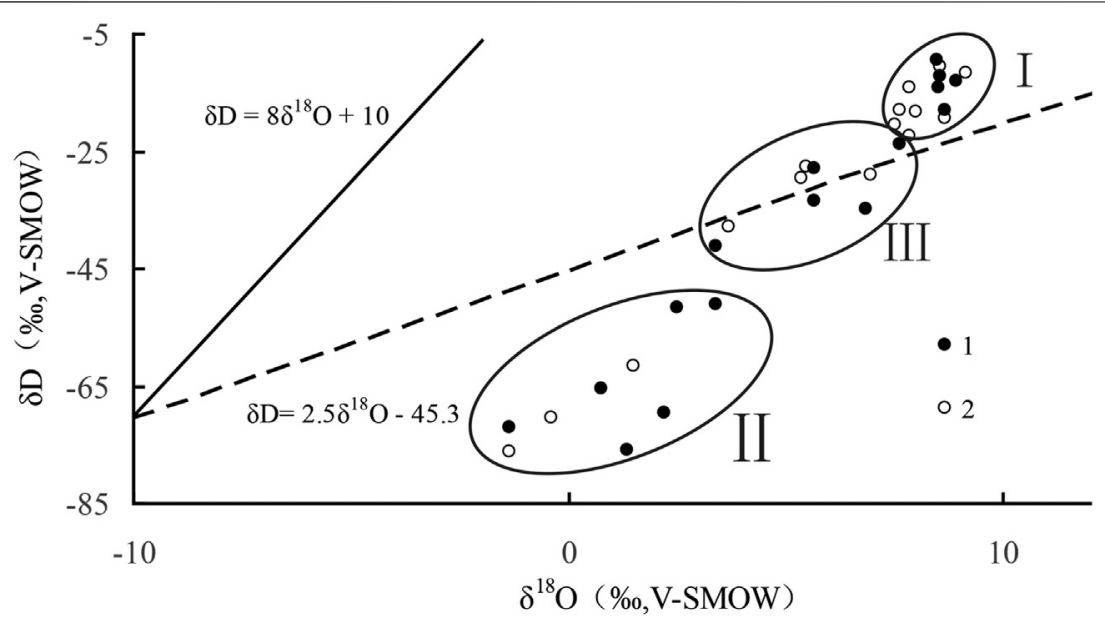

FIGURE $6 \mid \delta^{18} \mathrm{O}$ vs. $\delta$ D graph of primary halite fluid inclusions in QSL. 1: ZK88-01; 2: ZK89-04; I, II, III: partitions. The full line is the Global Meteoricwater Line of Craig, and the dotted line is the evaporation line in the QSL area from Zhang et al. (1995).

FIGURE 7| Change characteristics about chemical composition of halite fluid inclusions.

waters after entering the salt precipitation stage, and their hydrochemical types have been reformed. Based on these, it is speculated that the sudden enrichment of $\mathrm{Sr}^{2+}$ and $\mathrm{Ca}^{2+}$, the second stage of salt formation in QSL, may be caused by the greatly enhanced activity of $\mathrm{Ca}-\mathrm{Cl}$ deep water, and more deep water supplies to the normally evolving salt lakes for mixing, resulting in the anomaly of ancient brine and minerals. In addition, combined with the characteristics of high concentration of chemical composition of halite fluid inclusions in the ISL1A core at the initial stage of salt formation, and the characteristics of high $\delta^{18} \mathrm{O}$ and $\delta \mathrm{D}$ values of ZK88-01 and ZK89-04 at the first stage and deviating from the evaporation line, it is speculated that $\mathrm{Ca}-\mathrm{Cl}$ deep water replenishment also has influence on the initial stage of salt formation in QSL. However, Ca-Cl deep water is weak in the third salt-forming stage and modern salt-forming process of QSL.

The comprehensive analysis of chemical composition, variation characteristics, and stable isotopes of ancient brine shows that the evolution of QSL is not a simple cycle of evaporation concentration-dilution desalination affected by climate fluctuations. The replenishment and mixing of $\mathrm{Ca}-\mathrm{Cl}$ deep water play an important role in the evolution of ancient brine and the formation of evaporation salt.

\section{Geochemical Anomalies at the Initial Stage of Salt Formation in QSL}

$\mathrm{Br}^{-}$in saline minerals/waters is an important indicator to reflect the degree and stage of the evaporation condition of the brine, and a higher content of $\mathrm{Br}^{-}$usually indicates a stronger evaporation of the salt lake and thus a higher concentration of brine (Sanders, 1991; Warren, 2006; Cheng et al., 2008; Farid et al., 2013; Zarei et al., 2013; Biehl et al., 2014; Zhao et al., 2020). However, the $\mathrm{Br}^{-}$content in the ISL1A core was abnormally high in the early stage of salt formation (Figure 7); it then decreased since $37.79 \mathrm{~m}$, re-increased in the late stage of salt formation, 


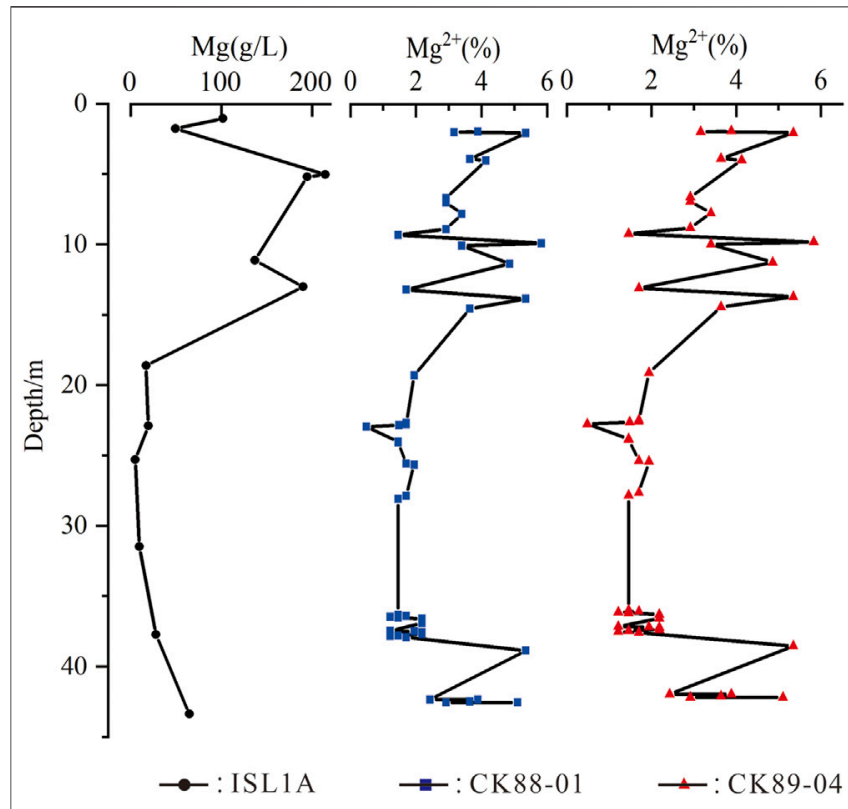

FIGURE 8 | Comparison of the $\mathrm{Mg}^{2+}$ concentration variation trend of halite fluid inclusions in boreholes ISL1A, CK88-01, and CK89-04 (the Mg ${ }^{2+}$ data in CK88-01 and CK89-04 from Zhang et al. (1993)).

began to rise again in the late stage of salt formation, and reached its peak at the location of potassium formation. The $\mathrm{Mg}^{2+}$ and $\mathrm{B}^{3+}$ contents are also good indicators to track the concentration of salt lake brine. Studies on different types of lakes in the Tibetan Plateau show that $\mathrm{Mg}^{2+}$ concentration in chloride lakes can well indicate the salinity of salt lakes (Wang and Wang, 2010). The study of $\delta^{11} \mathrm{~B}$ and $\rho\left(\mathrm{B}^{3+}\right)$ in salt lakes of the $\mathrm{QB}$ shows that there is a significant positive correlation between them, indicating $\mathrm{B}^{3+}$ contents can be used as an index to reconstruct the salinity of ancient lakes in arid areas (Liu et al., 2000; Du et al., 2019; Zhang et al., 2019). The variations of $\rho\left(\mathrm{Br}^{-}\right), \rho\left(\mathrm{Mg}^{2+}\right)$, and $\rho\left(\mathrm{B}^{3+}\right)$ are therefore used to reflect the variation of salinity in QSL and the characteristics of high brine concentration in the initial stage of salt formation. The $\mathrm{B}^{3+}$ and $\mathrm{Mg}^{2+}$ variations in halite of the ISL1A borehole were analyzed by Fan et al. (2015), and they proposed that the contents of $\mathrm{B}^{3+}$ and $\mathrm{Mg}^{2+}$ stem primarily from halite fluid inclusions, rather than salt minerals. According to the characteristics of high concentration of halite fluid inclusions $\rho\left(\mathrm{Mg}^{2+}\right), \rho\left(\mathrm{B}^{3+}\right), \rho\left(\mathrm{Br}^{-}\right)$, and $\rho\left(\mathrm{K}^{+}\right)$in the early stage of salt formation in the ISL1A borehole (Figure 7 ), the salinity of lake water in QSL is relatively high during this interval.

In the CK6 borehole located in the Bieletan section, the transition between the halite layer at the bottom and the underlying clastic layer is also abrupt, accompanied by a sudden appearance of salt minerals (Huang and Han, 2007). The cores CK89-04 and CK88-01 are located in the northern edge of Dabuxun Lake, close to the studied ISL1A (Figure 1B). The evaluation and comparison of lake sediment ages in QSL show that the salt-forming periods of ISL1A, CK89-04, and CK88-01 cores are almost the same (Fan et al., 2014). Therefore, we compared the $\mathrm{Mg}^{2+}$ results in halite fluid inclusions of the three boreholes and found that the variation tendency of $\mathrm{Mg}^{2+}$ in the upper evaporation strata in the ISL1A borehole is almost consistent with that of $\mathrm{Mg}^{2+}$ in the other two boreholes (Figure 8). The change in $\mathrm{Mg}^{2+}$ content can indicate the evolution degree of salt lake brine (Zhang et al., 1993). It also reflects the characteristics of high brine concentration at the initial stage of salt formation in QSL and the general evolution trend of the salt lake. As far as the evolution law of salt lakes is concerned, the salinity of water is generally a process from low to high, but the chemical characteristics of ancient lake water represented by halite fluid inclusions and the actual deposition of boreholes are not the case. However, these high-concentration elements, other than $\mathrm{Na}^{+}$and $\mathrm{Cl}^{-}$, did not appear in the diffraction results of borehole minerals; these elements did not form salt minerals but were dispersed in brine and wrapped in halite inclusions, which confirmed the existence of high-salinity brine in this period. At least the existence of water rich in $\mathrm{Na}^{+}$, $\mathrm{Cl}^{-}, \mathrm{Mg}^{2+}, \mathrm{B}^{3+}, \mathrm{K}^{+}$, and $\mathrm{Br}^{-}$led to geochemical anomalies in the early stage of salt formation in QSL.

There are two explanations for this abrupt salt formation in QSL provided by previous studies. Firstly, the neotectonic activity in the late Pleistocene facilitates the uplift of the Kunlun Mountain, leading to the transfer of sulfate-type ancient lake water in the East Kunlun Mountain by rivers to Qarhan, making it enter suddenly into the salt-forming stage (Zhu et al., 1990). Secondly, the tectonic activity caused the uplift in the west and the decline in the east of the $\mathrm{QB}$, forcing the supersaturated $\mathrm{NaCl}$ brine in the west to migrate eastward, promoting Qarhan to enter suddenly into the salt-forming stage (Huang and Han, 2007). All the above conclusions are indirect speculations, and there is no direct evidence to prove that the migration of ancient water bodies caused the sudden salt formation in QSL. Especially in the East Kunlun area, the water supply is diverse and the environment is humid, so it is debatable whether the ancient lake evolved to the salt lake stage. Furthermore, these studies suggest the tectonic activity as the key driving factor for the sudden formation of salt layers in QSL, but they did not further reveal this important tectonic activity. Chen et al. (2011) divided the terrace of the Golmud River into two stages: the filling period of the Sancha River in $82-16 \mathrm{ka}$ and the cutting period of the Golmud River since $16 \mathrm{ka}$, and considered that structural stability is the basis of filling in $82-16 \mathrm{ka}$, while the cutting period since $16 \mathrm{ka}$ is driven by tectonic uplift. The research on sediments and alluvial fans in the Xidatan-Golmud drainage shows that the river terraces lasting before $30 \mathrm{ka}$ are in the stage of filling and alluvial fan formation (Owen et al., 2006). The stable tectonic environment of the Sancha River in the Golmud River during the filling period is further explained. The study of tectonic stages of the Qilian Mountain in the adjacent area since Quaternary shows that there are at least five tectonic uplift activities, and the most recent one is about $80 \mathrm{ka}$ (Guo et al., 2016). It suggests that the structure of QSL is not active at the initial stage of salt formation, and the suddenness of its initial salt formation should not be driven by tectonic activities. It suggests that the tectonic uplift drove the supersaturated $\mathrm{NaCl}$ brine in the west to migrate to QSL and caused it suddenly to form salt, which needs further demonstration. 
Halite deposition suddenly started at $52 \mathrm{~m}$ in the ISL1A borehole, the semi-quantitative content of halite suddenly increased from $5 \%$ in the clastic layer to $30 \%$, and the average value of the semi-quantitative content of halite reached $60 \%$ at $45 \mathrm{~m}$, which started the first salt-forming period (An, 2012). In addition, the boron isotope results of carbonate in the ISL1A borehole show that the boron isotope content suddenly increases at about $52 \mathrm{~m}$, which is thought to be caused by the sudden increase in lake salinity (Zhang., 2020). Paleoclimate was reconstructed by clay minerals and fossil pollen from the ISL1A borehole; the climate in the study area began to become dry and cold at about $53 \mathrm{ka}$, which led to the evolution of lake to salt lake (Wei et al., 2015; Miao et al., 2016). The results suggest that the abnormally high $\rho\left(\mathrm{Mg}^{2+}\right)$, $\rho\left(\mathrm{B}^{3+}\right), \rho\left(\mathrm{Br}^{-}\right)$, and $\rho\left(\mathrm{K}^{+}\right)$in fluid inclusions of halite in the first stage of this study reflect the late stage of the first normal saltforming period in QSL. This salt-forming event resulted in the high concentration of ancient brine in the early stage of salt formation. The study of $\delta^{18} \mathrm{O}$ and $\delta \mathrm{D}$ in QSL shows that although the isotopic composition in the first salt formation stage of the salt lake is stable, it deviates slightly from the evaporation line in the study area (Figure 6), reflecting that the hydrological characteristics of the lake are not completely controlled by evaporation factors. This study holds that the high concentration in the early stage of salt formation in QSL is caused by a normal salt formation event, so there is no sudden large-scale supply of other water to the salt lake. Meanwhile, one study has confirmed that the $\delta^{18} \mathrm{O}$ and $\delta \mathrm{D}$ values of lake water lie on the evaporation line of the study area (Zhang et al., 1991), and its supply will not cause $\delta^{18} \mathrm{O}$ and $\delta \mathrm{D}$ of lake water to deviate from the evaporation line. Therefore, it is speculated that the replenishment of $\mathrm{Ca}-\mathrm{Cl}$ deep water with high salt content has impact on the hydrological characteristics of lakes. However, the replenishment amount is not as significant as that in the second stage, and the contents of $\rho\left(\mathrm{Ca}^{2+}\right), \rho\left(\mathrm{Sr}^{2+}\right)$, $\rho\left(\mathrm{Li}^{+}\right)$, and $\rho\left(\mathrm{Rb}^{+}\right)$in halite fluid inclusions do not increase significantly (Figure 7). This is the reason why $\delta^{18} \mathrm{O}$ vs. $\delta \mathrm{D}$ deviates from the evaporation line in the study area for a small distance.

\section{$\mathrm{Ca}^{2+}$ and $\mathrm{Sr}^{2+}$ Anomalous Enrichment in the Late Stage of Halogenases in QSL}

The average value of $\delta \mathrm{D}$ of primary halite fluid inclusions in boreholes CK89-04 and CK88-01 is $-35.2 \%$, which is considered to be due to the deuterium-poor external water mixed in the whole process of primary halite precipitation in QSL, and it is considered that water may be the deuterium-poor water in the deep fault zone about the northern margin of the lake area (Zhang et al., 1990; Zhang et al., 1993). The peak value of $\rho\left(\mathrm{Ca}^{2+}\right)$ and $\rho\left(\mathrm{Sr}^{2+}\right)$ in ISL1A is in the No. 5 sample at $11.5 \mathrm{~m}$, which is basically in the same stratum as $\delta \mathrm{D}$ of CK89-04 and CK88-01. Deuterium deficiency is the characteristic of deep water; the smaller the $\delta \mathrm{D}$ value, the larger the proportion of deep water (Zhang et al., 1993), and the corresponding contents of $\rho\left(\mathrm{Ca}^{2+}\right)$ and $\rho\left(\mathrm{Sr}^{2+}\right)$ are higher. According to the characteristics of $\delta \mathrm{D}$ and $\delta^{18} \mathrm{O}$ of boreholes, the evolution of QSL can be divided into three

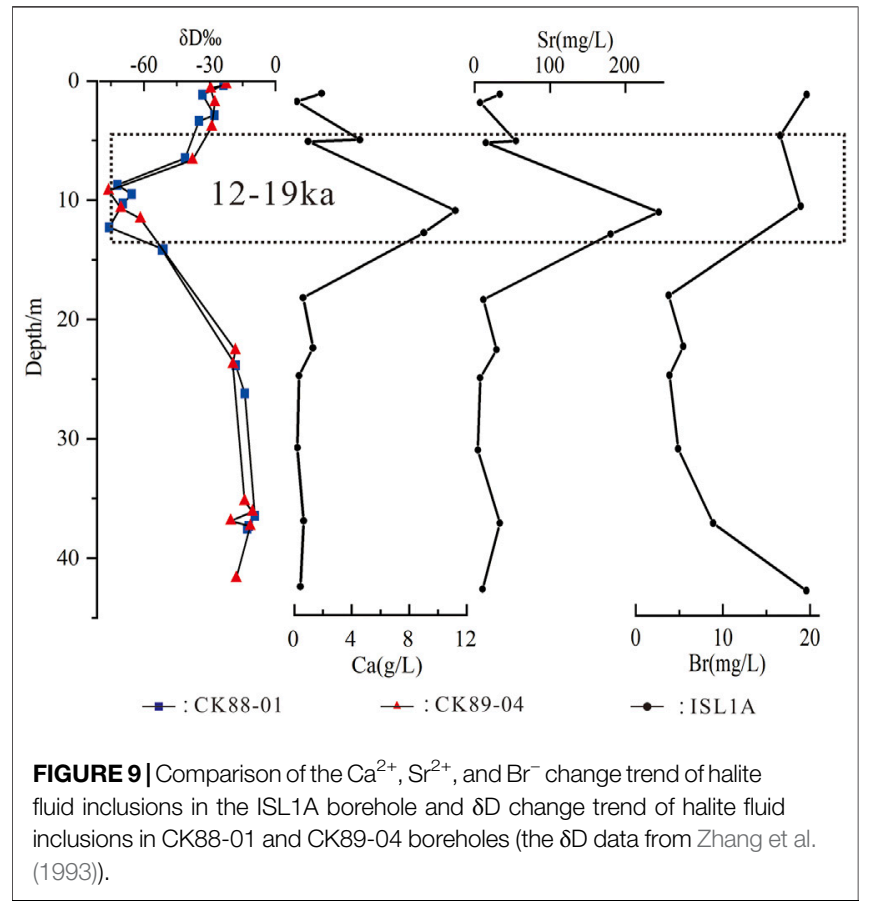

stages; the sedimentary stage of 8-24 m spans $15-21 \mathrm{ka}$, which is in the great ice age of the last glacial stage (Lowenstein et al., 1994; Yang et al., 1995; Zhang et al., 1995). Combining the low $\delta \mathrm{D}$ interval of CK89-04 and CK88-01 with the high $\rho\left(\mathrm{Mg}^{2+}\right), \rho\left(\mathrm{K}^{+}\right)$, $\rho\left(\mathrm{Ca}^{2+}\right)$, and $\rho\left(\mathrm{Sr}^{2+}\right)$ intervals of ISL1A (Figure 7), the geological time is limited to $12-19 \mathrm{ka}$ (Figure 9). As mentioned earlier, the potassium salt in QSL mainly occurs in the $S_{4}$ layer in the late stage of salt formation. In view of the high enrichment characteristics of $12-19 \mathrm{ka}$ ions, it is inferred that this period should reflect the $\mathrm{S}_{4}$ potassium salt layer in QSL. Compared with the deep sea oxygen isotope, it is found that the great ice age of the last glacial stage appeared in the northern margin of the Qinghai-Tibet Plateau in 21-15 ka (Zhang et al., 1995). Major elements and stable isotopes in primary halite fluid inclusions show that QB climate is extremely dry and cold during 20-11 ka (Lowenstein et al., 1994; Yang et al., 1995). As far as paleoclimate is concerned, during the period of $12-19 \mathrm{ka}$, the study area is dry and has low temperature, which is suitable for salt formation. However, the negative correlation between $\rho\left(\mathrm{Ca}^{2+}\right), \rho\left(\mathrm{Sr}^{2+}\right)$, and $\delta \mathrm{D}$ in ancient brine of QSL during the period of $12-19 \mathrm{ka}$ (Figure 9) also indicates a sudden increase in the recharge of $\mathrm{Ca}-\mathrm{Cl}$ deep water during this interval. Moreover, the abrupt increase in $\rho\left(\mathrm{Ca}^{2+}\right)$ and $\rho\left(\mathrm{Sr}^{2+}\right)$ was also accompanied by a sharp increase in $\rho\left(\mathrm{Mg}^{2+}\right), \rho\left(\mathrm{K}^{+}\right), \rho\left(\mathrm{Li}^{+}\right)$, and $\rho\left(\mathrm{Rb}^{+}\right)$. This abrupt increase in multi-ions during $12-19 \mathrm{ka}$ cannot be solely explained by climate change, and we suggest that the increased supply of $\mathrm{Ca}-\mathrm{Cl}$ deep water should also play an important role. The reason for the increase of $\mathrm{Ca}-\mathrm{Cl}$ deep water supply in the potassium-magnesium salt deposition stage is still unclear.

Based on the variations characteristics of fluid inclusion composition in halite and related evidence, we consider that the abrupt increase in the ion content from 19 to $12 \mathrm{ka}$ in QSL and 
more Ca-Cl-type deep water supply to the salt lake are driven by tectonic activities. The study on river terraces developed in the northeastern margin of the Tibetan Plateau relates river terraces to the combined effects of climate change and tectonic uplift (Gao et al., 2008). The Golmud River, as an important regional water system, preserves the tectonic activity and climate change information in this area. The stream trenching of the Golmud River since $16 \mathrm{ka}$ was suggested to be driven by the regional tectonic activity (Chen et al., 2011). A systematic study on the chronology of river terraces of the Kunlun River, Hongshui River, and Halaguole River developed in the East Kunlun Mountains (Wang et al., 2009) indicates that these rivers have developed river terraces during the period of $21.9-12.9 \mathrm{ka}$, and the characteristics of terraces are consistent with the characteristics of intermittent tectonic uplift with strong frequency but small amplitude. A study on the lake surface change in Great Qaidam shows that the last replenishment time of the Yuka River to Great Qaidam Lake is about 23-17 ka, without further replenishment (Madsen et al., 2013). They also speculated that the river diverted from the Great Qaidam Lake system due to the sharp downcutting of the river. According to the development time of river terraces in the surrounding water systems of the study area, terraces were developed in all major rivers during this period (19-12 ka) and were significantly uplifted by tectonic activity. In view of this, we speculate that the reason for the enhancement of $\mathrm{Ca}-\mathrm{Cl}$ deep water activity is the neotectonic activity during this period, which leads to the ion content increase of $\mathrm{Ca}^{2+}, \mathrm{Sr}^{2+}$, etc., during 12-19 ka.

\section{Re-Recognition of Halogenases in QSL}

It is known that there exist three salt-forming periods in past $50 \mathrm{ka}$ in QSL (Zhang et al., 1990; Yang et al., 1995; Zhang et al., 1995; Fan et al., 2018; Du et al., 2019; Zhang, 2020). However, as the most direct index of ancient brine research, in terms of the evolution process of QSL revealed by the chemical composition of halite fluid inclusions, it directly reveals the unique advantages of the chemical composition of ancient brine, which contributes to a comprehensive understanding of the salt formation process of QSL. Firstly, there is a geochemical anomaly in the early stage of salt formation in QSL, which is considered to be caused by a normal salt formation event. Secondly, the direct evidence shows that, in the late stage of salt formation and potassium formation in QSL, there is a phenomenon of increase in deep Ca-Cl water supply, which is speculated to be driven by tectonic activities.

The river water and $\mathrm{Ca}-\mathrm{Cl}$ deep water are currently two main sources supplying waters to QSL. Although the mixed of two kinds of water runs through the whole process of salt formation in QSL, the solid potassium did not appear in the whole salt formation process, only forms in $\mathrm{S}_{4}$ salt layer. Although $\mathrm{Ca}-\mathrm{Cl}$ deep water in the northern margin of QSL is rich in $\mathrm{Ca}^{2+}$ and $\mathrm{Sr}^{2+}$, the content of $\mathrm{K}^{+}$is not enriched (Lowenstein and Risacher, 2009; Fan et al., 2018) due to the mixing process of $\mathrm{Ca}-\mathrm{Cl}$ deep water and magnesium sulfate subtype river water, which is beneficial to the enrichment of potassium (Yuan, 1995). In addition to the evolution of salt lakes to salt playas and frequent climate fluctuations under the general trend of drought, the mixing process is necessary for potassium salt formation in QSL (Zhang et al., 1993). Based on the study of chemical composition of ancient brine, combined with geological age and tectonic activities, the most direct evidence indicates that the activity of $\mathrm{Ca}-\mathrm{Cl}$ deep water increased and the recharge increased in the formation stage of potassium salt in QSL. It suggests that the increase in $\mathrm{Ca}-\mathrm{Cl}$ deep water supply driven by tectonic activities plays an important role in the formation of potassium salt in QSL.

In order to study the salt-forming evolution process of salt lakes in the QB, a basin with active tectonic activities and complex hydrogeological conditions (deep oilfield brine development), we must consider the specific influence of deep water on salt lake evolution and the connection between deep water and tectonic activities. In addition, while using the core profile of the evaporite basin to study paleoclimate, it is also necessary to consider the specific influence of deep water and tectonic activities on the sedimentary evolution of salt lakes and eliminate their influence on the salt formation process. In this way, we will get the saltforming process and paleoclimate results that are closest to the truth.

\section{CONCLUSIONS}

(1) The formation of the main potassium salt layer in QSL and the massive replenishment and mixing process of $\mathrm{Ca}-\mathrm{Cl}$ deep water are the key factors, and it is speculated that the increase in replenishment is due to tectonic activities.

(2) The geochemical anomaly characteristics in the early stage of salt formation in QSL are analyzed and speculated to be caused by a salt-forming event besides $\mathrm{Ca}$-Cl deep water that may also have some influence, which is hardly irrelevant to tectonic activities.

(3) Re-recognition of halogenases in QSL shows that there are many factors affecting the evolution of salt formation in the salt lake, which need to be explored continuously. Among them, deep water has an important impact; the salt lake as a carrier to carry out research must take into account its factors.

\section{DATA AVAILABILITY STATEMENT}

The original contributions presented in the study are included in the article/Supplementary Material, and further inquiries can be directed to the corresponding authors.

\section{AUTHOR CONTRIBUTIONS}

JL involved in data analysis and article writing. XZ provided ideas for writing the article and paid for testing. $\mathrm{MH}$ tested and corrected data. JL and WL pretreated the sample. WL tested the sample. WM analyzed core sedimentation characteristics and gave sampling guidance. XZ and WM revised the article. XY, YL and QT performed field core sedimentation edits and sample 
selection. WH gave a lot of suggestions on the logic and language expression of the article. HM selected the area for drilling construction and paid the drilling construction cost.

\section{FUNDING}

This research was supported by the National Natural Science Foundation of China (Grant Nos. 41672087, 41402082 and

\section{REFERENCES}

An, F., Ma, H., Wei, H., Fan, Q., and Han, W. (2013). Grain-size Distribution Patterns of Lacustrine Sediments of Qarhan Area and its Environmental Significance. Arid Geogr. 36 (2), 212-220. doi:10.13826/j.cnki.cn65-1103/ x.2013.02.009

An, F. (2012). Paleoenvironmental and Paleolake Evolution, Aeolian Component Record in Lacustrine Sediments and its Atmospheric Circulation Signifificance since $93 \mathrm{Ka}$ in Qarhan Area, Qaidam Basin. [Beijing: Graduate University of Chinese Academy of Sciences. [dissertation thesis] [in Chinese]

Benison, K. C., and Goldstein, R. H. (1999). Permian Paleoclimate Data from Fluid Inclusions in Halite. Chem. Geology. 154, 113-132. doi:10.1016/S0009-2541(98) 00127-2

Biehl, B. C., Reuning, L., Strozyk, F., Kukla, P. A., Reuning, L., and Strozyk, F. (2014). Origin and Deformation of Intra-salt Sulphate Layers: an Example from the Dutch Zechstein (Late Permian). Interational J. Earth Sciceces 103 (3), 697-712. doi:10.1007/s00531-014-0999-4

Chen, K., Yang, S., and Zheng, X. (1981). The Salt Lakes on the Qinghai-Xizang Plateau. Acta Geogr. Sin. 36, 13-21. [in Chinese]

Chen, Y., Li, Y., Zhang, Y., Zhang, M., Zhang, J., Yi, C., et al. (2011). Late Quaternary Deposition and Incision Sequences of the Golmud River and Their Environmental Implication. Quat. Sci. 31 (02), 347-359. doi:10.3969/ 1001-7410.2011.02.17[in Chinese]

Cheng, H., Ma, H., Tan, H., Xu, J., and Zhang, X. (2008). Geochemical Characteristics of Bromide in Potassium Deposits: Review and Research Perspectives. Bull. Mineralogy, Pet. Geochem. 27 (4), 399-408. doi:10.1016/ S1872-5791(08)60056-1[in Chinese]

Du, Y., Fan, Q., Gao, D., Wei, H., Shan, F., Li, B., et al. (2019). Evaluation of boron Isotopes in Halite as an Indicator of the Salinity of Qarhan Paleolake Water in the Eastern Qaidam Basin, Western China. Geosci. Front. 10, 253-262. doi:10.1016/j.gsf.2018.02.016

Fan, Q., Lowenstein, T., Wei, H., Yuan, Q., Qin, Z., Shan, F., et al. (2018). Sr Isotope and Major Ion Compositional Evidence for Formation of Qarhan Salt Lake, Western China. Chem. Geology. 497, 128-145. doi:10.1016/09.001

Fan, Q., Ma, H., Ma, Z., Wei, H., and Han, F. (2014). An Assessment and Comparison of ${ }^{230} \mathrm{Th}$ and AMS ${ }^{14} \mathrm{C}$ Ages for Lacustrine Sediments from Qarhan Salt Lake Area in Arid Western China. Environ. Earth Sci. 71, 1227-1237. doi:10.1007/s12665-013-2526-5

Fan, Q., Ma, Y., Cheng, H., Wei, H., Yuan, Q., Qin, Z., et al. (2015). Boron Occurrence in Halite and boron Isotope Geochemistry of Halite in the Qarhan Salt Lake, Western China. Sediment. Geology. 322, 34-42. doi:10.1016/ j.sedgeo.2015.03.012

Farid, I., Trabelsi, R., Zouari, K., Abid, K., and Ayachi, M. (2013). Hydrogeochemical Processes Afecting Groundwater in an Irrigated Land in Central Tunisia. Environ. Earth Sci. 68 (5), 1215-1231. doi:10.1016/ j.jafrearsci.2012.10.001

Gao, H., Liu, X., Pan, B., Wang, Y., Yu, Y., and Li, J. (2008). Stream Response to Quaternary Tectonic and Climatic Change: Evidence from the Upper Weihe River, central China. Quat. Int. 186 (1), 123-131. doi:10.1016/j.quaint.2007.08.046

Goldstein, R. H., and Reynolds, T. J. (1994). Systematics of Fluid Inclusions in Diagenetic Minerals: SEPM Short Course 31. Oklahoma: Society for Sedimentary Geology press.
42071111) and Foundation of Qinghai Science \& Technology Department (Grant No. 2014-ZJ-704).

\section{ACKNOWLEDGMENTS}

We thank two reviewers for their valuable suggestions and comments on the manuscript. We are also grateful to Special Issues convener, editors and typesetters.

Guo, H., Yang, L., Zhu, X., Zhu, T., Yue, L., Wu, H., et al. (2016). River Terrace and Quaternary Tectonic Uplift in the Qilian Mountain. Geol. Bull. China 35 (12), 2033-2044. doi:10.3969/j.issn.1671-2552.2016.12.011

He, M., Luo, C., Yang, H., Kong, F., Li, Y., and Deng, L. (2020). Sources and a proposal for comprehensive exploitation of lithium brine deposits in the Qaidam Basin on the northern Tibetan Plateau, China: Evidence from Li isotopes. Geol. Rev. 117, 1-7. doi:10.1016/j.oregeorev.2019.103277

Hardie, L. A., Lowenstein, T. K ., and Spencer, R. J. (1983). The Problem of Distinguishing between Primary and Secondary Features in Evaporites. Sixth Int. Symp. Salt 1, 11-39.

Hu, D. (1991). Metamorphism and Deformation Regularity of Modern Sediments in the Qarhan Salt Lake, Qinghai, China. Geotectonica et Metallogenia 15 (3), 243-254. doi:10.16539/j.ddgzyckx.1991.03.009 [in Chinese]

Hu, D. (1990). Rediscussion on the Tectonic Evolution of Qarhan Salt Lake Deposit. Hunan: Hunan Normal University press [in Chinese]

Hu, M., He, H., Zhan, X., Fan, X., Wang, G., and Jia, Z. (2008). Matrix Normalization for Insitumulti-Element Quantitative Analysis of Zircon in Laser Ablation Inductively Coupled Plasma Mass Spectrometry. Chin. J. Anal. Chem. 36 (7), 947-953. doi:10.3321/j.issn:0253-3820.2008.07.016

Huang, Q., and Cai, B. (1987). Geochronological Study on the Sediments in Qarhan lake. China-Australia Conference on Quaternary Cooperation, 106-114. [in Chinese]

Huang, Q., and Han, F. (2007). Evolution of Salt Lakes and Palaeoclimate Fluctuation in Qaidam Basin. Beijing: Science Press [in Chinese]

Li, Q., Fan, Q., Wei, H., Qin, Z., Zhang, X., Du, Y., et al. (2020). Sulfur Isotope Constraints on the Formation of $\mathrm{MgSO}_{4}$-Deficient Evaporites in the Qarhan Salt Lake, Western China. J. Asian Earth Sci. 189, 1-11. doi:10.1016/ j.jseaes.2019.104160

Li, R., Liu, C., Jiao, P., Liu, W., Tang, D., and Wang, S. (2020). The Effect of Solvent Chemistry on Potassium Dissolution Extraction from Low-Grade Solid Potash Ore in Qarhan Salt Lake, China. Appl. Geochem. 115, 1-11. doi:10.1016/ j.104550

Liu, W., Xiao, Y., Peng, Z., An, Z., and He, X. (2000). Boron Concentration and Isotopic Composition of Halite from Experiments and Salt Lakes in the Qaidam Basin. Geochimica et Cosmochimica Acta 64 (13), 2177-2183. doi:10.1016/ S0016-7037(00)00363-X

Liu, X., Cai, K., and Yu, S. (2002). Geochemical Simulation of Formation and Evolution of Salt Lakes and Their Water Sources in Qardam Basin: Application of Pitzers Model. Geochimica 31 (05), 501-507. doi:10.19700/j.03791726.2002.05.012

Longerich, H. P., Jackson, S. E., and Gunther, D. (1996). Inter-laboratory Note Laser Ablation Inductively Coupled Plasma Mass Spectrometric Transient Signal Data Acquisition and Analyte Concentration Calculation. J. Anal. At. Spectrom. 11 (09), 899-904. doi:10.1039/JA9961100899

Lowenstein, T. K., and Hardie, L. A. (1985). Criteria for the Recognition of Salt-pan Evaporites. Sedimentology 32, 627-644. doi:10.1111/j.13653091.1985.tb00478.x

Lowenstein, T. K., and Risacher, F. (2009). Closed basin brine evolution and the influence of $\mathrm{Ca}-\mathrm{Cl}$ inflow waters: death Valley and Bristol Dry Lake California, Qaidam Basin, China, and Salar de Atacama, Chile. Aquetic Geochem. 15, 71-94. doi:10.1007/s10498-008-9046-Z

Lowenstein, T. K., Spencer, R. J., Yang, W., Casas, E., Zhang, P., Zhang, B., et al. (1994). Major-element and Stable-Isotope Geochemistry of Fluid Inclusionsin Halite, Qaidam Basin, Western China: Implications for Late Pleistocene/ 
Holocene Brine Evolution and Paleoclimates. Geol. Soc. America Spec. Pap. 289, 19-32. doi:10.1130/SPE289-p19

Lowenstein, T. K., Spencer, R. J., and Zhang, P. (1989). Origin of Ancient Potash Evaporites: Clues from the Modern Nonmarine Qaidam Basin of Western China. Science 245, 1090-1092.

Madsen, D. B., Lai, Z., Sun, Y., Rhode, D., Liu, X., and Brantingham, P. J. (2013). Late Quaternary Qaidam lake Histories and Implications for an MIS3 "Greatest Lakes" Period in Northwest China. J. Paleolimnology 51, 161-177. doi:10.1007/ s10933-012-9662-x

Meng, F., Liu, C., and Ni, P. (2012). To Forecast Sylvite Deposits Using the Chemistry of Fluid Inclusions in Halite. Acta Micropalaeontogica Sinica 29 (1), 62-69. [in Chinese]

Meng, F., Ni, P., Yan, X., Wang, T., Yan, K., Wang, G., et al. (2011). Chemical Composition of the Ancient lake at JinTan Salt Mine: Evidence from Fluid Inclusions in Halite. Acta Micropalaeontogica Sinica 28 (3), 324-328. doi:10.1631/jzus.B1000197[in Chinese]

Miao, W., Fan, Q., Wei, H., Zhang, X., and Ma, H. (2016). Clay Mineralogical and Geochemical Constraints on Late Pleistocene Weathering Processes of the Qaidam Basin, Northern Tibetan Plateau. J. Asian Earth Sci. 127, 267-280. doi:10.1016/j.jseaes.2016.06.013

Owen, L. A., Finkel, R. C., Ma, H., and Barnard, P. (2006). Late Quaternary Landscape Evolution in the Kunlun Mountains and Qaidam Basin, Northern Tibet: A Framework for Examining the Links between Glaciation, lake Level Changes and Alluvial Fan Formation. Quat. Int. 154-155, 73-86. doi:10.1016/ 02.008

Ren, S., Ge, X., Yan, Z., Lin, Y., Hu, Y., Liu, Y., et al. (2006). Application of ${ }^{36} \mathrm{Cl}-$ Dating to the Last Rapid Uplift of the Tibet Plateau. Acta Geologica sinica 80 (8), 1110-1117. doi:10.3321/j.issn:0001-5717.2006.08.003[in Chinese]

Sanders, L. L. (1991). Geochemistry of Formation Waters from the Lower Silurian Clinton Formation (Albion Sandstone), Eastern Ohio. AAPG Bull. 75 (10), 1593-1608. doi:10.1061/(ASCE)0733-9410(1991)117:11(1831.2)

Sun, D., and Lock, D. (1988). Formation of Potash Deposits in Qaidam Basin. Sci. China 18 (12), 1323-1333. Available at: http://ir.isl.ac.cn/handle/363002/1420 [in Chinese]

Sun, X., Hu, M., Liu, C., Jiao, P., Ma, L., Wang, X., et al. (2013). Composition Determination of Single Fluid Inclusions in Salt Minerals by Laser Ablation ICPMS. Chin. J. Anal. Chem. 41 (02), 235-241. doi:10.1016/S1872-2040(13)60631-3

Wang, A., Smith, J. A., Wang, G., Zhang, K., Xiang, S., and Liu, D. (2009). Late Quaternary River Terrace Sequences in the Eastern Kunlun Range, Northern Tibet: A Combined Record of Climatic Change and Surface Uplift. J. Asian Earth Sci. 34, 532-543. doi:10.1016/j.jseaes.2008.09.003

Wang, H., and Wang, Y. (2010). Preliminary Analysis on $\mathrm{Mg}^{2+}, \mathrm{Ca}^{2+}$ and $\mathrm{Mg} / \mathrm{Ca}$ as Salinity Indicators of Lakes in the Qinghai-Tibetan Plateau. J. Lake Sci. 22 (6), 849-900. doi:10.1080/09500340.2010.529951[in Chinese]

Warren, J. K. (2006). Evaporites: Sediments, Resources and Hydrocarbons. Berlin: Springer-Verlag Berlin Heidelberg.

Wei, H., Fan, Q., Zhao, Y., An, F., Shan, F., Ma, H., et al. (2016). Chemical Elements in Core Sediments of the Qarhan Salt Lake and Palaeoclimate Evolution during 94-9 Ka. Acta Geoscientica Sinica 37 (2), 193-203. doi:10.3975/cagsb.2016.02.07 [in Chinese]

Wei, H., Fan, Q., Zhao, Y., Ma, H., Shan, F., An, F., et al. (2015). A 94-10 Ka Pollen Record of Vegetation Change in Qaidam Basin, Northeastern Tibetan Plateau. Palaeogeogr. Palaeoclimatol. Palaeoecol. 431, 43-52. doi:10.1016/ j.palaeo.2015.04.025

Weldgehebriel, M. F., Lowenstein, T. K., Veigas, J. G., Collins, D., Sendula, E., Bodnar, R. J., et al. (2020). Combined LA-ICP-MS and Cryo-SEM-EDS: an Improved Technique for Quantitative Analysis of Major, Minor, and Trace Elements in Fluid Inclusions in Halite. Chem. Geology. 20, 1-46. doi:10.1016/ j.chemgeo.2020.119762

Yang, Q. (1982). The Sedimentation Mechanism of Potash Deposits in the Qarhan Inland Salt lake. Acta Geologica Sinica 03, 281-292. doi:10.1007/BF01093415

Yang, W., Spencer, R. J., Krouse, H. R., Lowenstein, T. K., and Casas, E. (1995). Stable Isotopes of lake and Fluid Inclusion Brines, Dabusun Lake, Qaidam Basin, Western China: Hydrology and Paleoclimatology in Arid Environments. Palaeogeogr. Palaeoclimatology, Palaeoecology. 117, 279-290. doi:10.1016/00310182(94)00126-S
Yi, J., Fan, Q., Wei, H., Wang, M., Qin, Z., Yuan, Q., et al. (2017). The Characteristics of the Mineral Assemblage and the Forming Clue in Qarhan Salt Lake. J. Salt Lake Res. 25 (02), 47-54. [in Chinese]

Yu, S. (2000). Potassium Brine Dynamics and Prediction in the First Mining Area of Qarhan Salt Lake. Beijing, China: Science Press.

Yuan, J., and Duan, Z. (1989). Mixation of Natural Waters and the Application of HW-Model to the Study of Mixation. Earth Science-Journal China Univ. Geosciences 14 (5), 553-561. [in Chinese]

Yuan, J. (1995). Formation Conditions of Potassium Salt deposit in Qarhan Salt Lake. Beijing, China: Science Press.

Yuan, J., Huo, C., and Cai, K. (1983). The High Mountain-Deep basin saline Environment-A New Genetic Model of Salt Deposits. Geol. Rev. 29 (02), 159-165. [in Chinese]

Yuan, J. (1959). Types of Salt Lakes in the Qaidam Basin. Acta Geol. Sinica 39 (3), 318-323. [in Chinese]

Zarei, M., Raeisi, E., Merkel, B. J., and Kummer, N. A. (2013). Identifying Sources of Salinization Using Hydrochemical and Isotopic Techniques, Konarsiah, Iran. Environ. Earth Sci. 70 (2), 587-604. doi:10.1007/s12665-012-2143-8

Zhang, B., Fan, H., Zhang, P., Lowenstein, T. K., and Spencer, R. J. (1990). Hydrogen and Oxygen Stable Isotope Analyses of Fluid Inclusions in Halite in Qarhan Salt lake with Geochemical Implications. Acta Sedimentologica Sinica 8 (1), 3-17. doi:10.1016/0925-8388(94)01490-6 [in Chinese]

Zhang, B., Zhang, P., Lowenstein, T. K., and Spencer, R. J. (1995). Time Range of the Great Ice Age of the Last Glacial Stage and its Related Geological Event of Playa in the Qinghai-Xizang (Tibet) Plateau. Quat. Sci. 3, 193-201. [in Chinese]

Zhang, P. (1987). Salt Lake in Qaidam Basin. Beijing, China: Science Press.

Zhang, P., Zhang, B., Lowenstein, T. K., and Spencer, R. J. (1991). On the Origin of Ancient Anomalous Evaporites: Evidence from Qaidam Basin. Geochimica 2, 134-143. doi:10.19700/j.0379-1726.1991.02.005[in Chinese]

Zhang, P., Zhang, B., Lowenstein, T. K., and Spencer, R. J. (1993). Origin of Ancient Potash Evaporites: Examples from the Formation of Potash of Qarhan Salt Lake in Qaidam Basin. Beijing, China: Science Press

Zhang, X. (2020). Boron Isotope Fractionation of Carbonates in Salt Lakes and its Tracer to the Evolution of the Qarhan Salt lake. [Beijing: University of Chinese Academy of Sciences. [dissertation thesis] [in Chinese]

Zhang, X., Li, Q., Qin, Z., Fan, Q., Du, Y., Wei, H., et al. (2019). Boron Isotope Geochemistry of a Brine Carbonate System in the Qaidam Basin, Western China. Sediment. Geol. 383, 293-302. doi:10.1016/ j.sedgeo.2019.02.011

Zhang, X., Xu, Z., Duan, Y., Ma, L., Meng, Z., Zhou, S., et al. (2003). Metabolic Pathway of the Quaternary Biogenetic Gases and Their Migration and Accumulation in the Qaidam Basin, China. Geol. Rev. 49 (2), 168-174. doi:10.1007/BF02873153[in Chinese]

Zhao, Y., Liu, C., Ding, T., Gonzalez, L., Li, Z., Wang, M., et al. (2020). Origin and depositional paleoenvironment of Triassic polyhalite in the Jialingjiang Formation, Sichuan Basin. Carbonates and Evaporites. Sediment. Geol. 35 (64), 1-17. doi:10.1007/s13146-020-00596-3

Zheng, X., Zhang, M., Xu, C., and Li, B. (2002). China Salt Lake Annals. Beijing: Science Press [in Chinese]

Zhu, Y., Li, Z., Wu, B., and Wang, M. (1990). The Formation of the Qarhan Salt Lakes as Viewed from the Neotectionic Movement. Acta Geol. Sinica 01, 13-21. [in Chinese]

Conflict of Interest: The authors declare that the research was conducted in the absence of any commercial or financial relationships that could be construed as a potential conflict of interest.

Copyright $\odot 2021 \mathrm{Li}$, Zhang, Hu, Li, Miao, Yuan, Li, Tang, Han and Ma. This is an open-access article distributed under the terms of the Creative Commons Attribution License (CC BY). The use, distribution or reproduction in other forums is permitted, provided the original author(s) and the copyright owner(s) are credited and that the original publication in this journal is cited, in accordance with accepted academic practice. No use, distribution or reproduction is permitted which does not comply with these terms. 